\title{
Short communication: Sensory characteristics and volatile organic compound profile of high-moisture mozzarella made by traditional and direct acidification technology
}

\author{
G. Natrella, ${ }^{1}$ M. Faccia, ${ }^{1 *}$ ๑ J. M. Lorenzo, ${ }^{2}$ P. De Palo, ${ }^{3} \oplus$ and G. Gambacorta ${ }^{1}$ \\ ${ }^{1}$ Department of Soil, Plant and Food Science, University of Bari, via G. Amendola 165/a, 70126 Bari, Italy \\ ${ }^{2}$ Centro Tecnológico de la Carne de Galicia, Rúa Galicia No 4, ParqueTecnológico de Galicia, San Cibrán das Viñas, 32900 Ourense, Spain \\ ${ }^{3}$ Department of Veterinary Medicine, University of Bari A. Moro, S.P. per Casamassima km 3, 70010, Valenzano, Bari, Italy
}

\begin{abstract}
In the present study, the sensory characteristics and the volatile organic compound (VOC) profiles of highmoisture mozzarella made by different acidification techniques were compared. The cheeses were manufactured at the same dairy by fermentation by autochthonous natural whey starter (traditional backslopping method) and direct acidification with citric acid (the most used industrial technology). Three cheesemaking trials were performed from February to June using raw milk from a single farm. The mozzarella samples were subjected to assessment of the chemical, microbiological, and sensory characteristics and to VOC analysis by headspace solid-phase microextraction coupled to gas chromatography-mass spectrometry. The relevant microbiological differences found between the 2 types of products were reflected in different sensory and VOC profiles. The cheeses were clearly discriminated by the panel, and traditional mozzarella had higher intensity attributes. The most discriminating descriptors were elasticity, overall odor and taste intensity, sour milk and fruity/vegetable odors, sour taste, and aftertaste. Even though some variability was observed among the trials, the VOC profile of traditional product was always much more complex than that obtained by direct acidification. In both products the carbonyl compounds were the most abundant chemical class, accounting for about $50 \%$ of the total. In detail, 51 compounds were identified in the entire set of samples, and their contribution to cheese aroma was roughly estimated by calculating the odor activity values on the basis of the odor thresholds available in the literature. The results allowed hypothesizing that only 12 of them could play a primary role. The most important among the odoractive compounds was 3-methyl-butanal that can both
\end{abstract}

Received June 3, 2019.

Accepted November 19, 2019.

*Corresponding author: michele.faccia@uniba.it derive from metabolism of lactic acid bacteria and yeasts. The results of the study may be very useful in view of European Union PDO labeling of the traditional product, in terms of protecting it from imitations.

Key words: mozzarella, acidification, volatile organic compound, 3-methyl-butanal

\section{Short Communication}

High-moisture mozzarella (HMM) is a fresh pasta filata cheese that originated in Italy in the 17th century. The production technology is based on acidification of the curd that determines casein demineralization and makes it stretchable in hot water. Curd acidification can be obtained by starter fermentation (traditional method) or by direct acidification of milk (industrial method). Direct acidification by addition of citric acid (CA) to milk is very popular in the dairy industry because it is cheaper and allows better standardization than starter fermentation (Faccia et al., 2009). In contrast, the traditional method is adopted in artisanal dairies, where an autochthonous whey starter called sieroinnesto (SI) is commonly used (backslopping method). Sieroinnesto is obtained by spontaneous fermentation of the whey kept warm $\left(38-42^{\circ} \mathrm{C}\right)$ for 12 to $24 \mathrm{~h}$ and represents one of the characterizing points for the Protected Designation of Origin (PDO) label that is currently under approval by the European Commission (EU, 2017). Unfortunately, the appearance of the cheese is independent of the acidification method used and it is very difficult for consumers to distinguish between the products. Research on the flavor of HMM is very scarce, and in view of the upcoming adoption of the PDO trademark, information is strongly needed. It is well known that aroma plays a primary role in cheese flavor: it can be defined as the odor-active part of the volatile fraction (Curioni and Bosset, 2002) containing several volatile organic compounds (VOC). The most used technique for investigating VOC in cheese is headspace solid-phase microextraction coupled to GC-MS. 
This has been applied to almost all popular cheeses but, to our knowledge, not yet to HMM. The few studies regarding the volatile compounds of this cheese have been carried out by different techniques: Moio et al. (1993a) and Pisano et al. (2016) used liquid-liquid partition, whereas Gasperi et al. (2001) directly applied proton transfer reaction MS. The present research aimed to assess the chemical-sensory characteristics of the upcoming PDO-labeled cow mozzarella in comparison to the industrial one, with particular emphasis on the VOC profile.

The study was conducted on mozzarella samples manufactured by traditional (SI fermentation) and direct acidification (addition of $\mathrm{CA}$ ) in a local dairy. The manufacturing protocols adopted were those commonly used in Southern Italy (Figure 1). Overall, 12 cheesemaking trials were carried out from February to June $(3$ trials $\times 2$ different technologies $\times 2$ replicates on the same day) using raw milk from a single farm. Milk was subjected to determination of $\mathrm{pH}$, fat, and protein (infrared analysis by Milko Scan FT1, Foss, Hillerød, Denmark), total viable counts (IDF, 1991), and SCC (Fossomatic FC, Foss). During processing, titratable acidity of the starter and $\mathrm{pH}$ of the curd samples were measured. The fresh cheese samples underwent analyses of $\mathrm{pH}$, moisture (oven drying), fat (Soxhlet method), and total protein (Kjeldahl method). The following microbial counts were done on starter and fresh cheese samples: mesophilic and thermophilic lactobacilli on de Man, Rogosa and Sharpe medium at 30 and $42^{\circ} \mathrm{C}$ for $48 \mathrm{~h}$, respectively; lactococci and streptococci on $\mathrm{M} 17$ agar at 30 and $42^{\circ} \mathrm{C}$ for $48 \mathrm{~h}$, respectively; enterococci on Slanetz and Bartley agar at $37^{\circ} \mathrm{C}$ for 48 $\mathrm{h}$; Pseudomonas spp. on Pseudomonas Agar Base with added CFC selective supplement, incubated at $25^{\circ} \mathrm{C}$ for $48 \mathrm{~h}$; Enterobacteriaceae on Violet Red Bile Glucose Agar incubated at $37^{\circ} \mathrm{C}$ for $24 \mathrm{~h}$; yeasts and molds on Yeast Extract Dextrose Chloramphenicol agar incubated at $30^{\circ} \mathrm{C}$ for $48 \mathrm{~h}$. All media were purchased from Oxoid Limited (Basingstoke, UK). The cheese sensory characteristics were evaluated by a panel composed of 8 trained assessors aged 25 to $58 \mathrm{yr}$, selected following the international standard (ISO, 1993). They were trained for a period of 3 mo (one session a week) during which they tasted 36 samples of table mozzarella taken from 5 different producers. During training, each panelist indicated a series of sensory attributes and quantified them using a 5-point numerical category scale (from $0=$ not perceived to $4=$ highly perceived). Only attributes with a weight percentage (frequency of citations $\times$ perceived intensity) greater than $30 \%$ were selected for evaluating the samples of the experimentation (Trani et al., 2016). Descriptive analysis was conducted on the samples during experimentation using the same scale used during training sessions. The CA and SI mozzarella samples (1 whole cheese weighing about $100 \mathrm{~g}$ ) were presented at $20^{\circ} \mathrm{C}$ within $15 \mathrm{~min}$ of each other, on a white dish marked with a 3 -digit code. The analysis was repeated 3 times for each cheesemaking trial, and the panelists received the samples in a random and balanced way so that each member evaluated the 2 mozzarella samples the same number of times. The VOC were investigated by headspace solidphase microextraction coupled to GC-MS. One gram of cheese sample was transferred into a $15-\mathrm{mL}$ glass vial (Supelco, Bellefonte, PA), added with $10 \mu \mathrm{L}$ of internal standard (3-pentanone) in water at $8.15 \mu \mathrm{g} /$ $\mathrm{mL}$ and $0.2 \mathrm{~g}$ of sodium chloride, and sealed with a screw cap with a silicone pierceable septum. The vials were kept at $37^{\circ} \mathrm{C}$ for $10 \mathrm{~min}$ for equilibration, then a triphasic fiber 50/30 $\mu \mathrm{m}$ of DVB/Carboxen/PDMS (Supelco) was inserted through the cap septum and exposed to the sample headspace for $15 \mathrm{~min}$ at the same temperature. Thereafter, the volatile compounds were desorbed by inserting the fiber for $2 \mathrm{~min}$ in the split/ splitless injector port of the GC set at $220^{\circ} \mathrm{C}$ (split ratio 1:18). The GC system was a Trace 1300 coupled with a single quadrupole ISQ mass spectrometer (Thermo Fisher Scientific, Rodano, Italy). The column used for separation was a TR-WAX MS $(20 \mathrm{~m}$ length $\times 0.1$ $\mathrm{mm}$ i.d. $\times 0.1 \mu \mathrm{m}$ film thickness, Agilent, Santa Clara, $\mathrm{CA})$. The chromatographic conditions were oven temperature $50^{\circ} \mathrm{C}$ for $0.1 \mathrm{~min}$, then to $180^{\circ} \mathrm{C}$ at $13^{\circ} \mathrm{C} / \mathrm{min}$ and to $220^{\circ} \mathrm{C}$ at $18^{\circ} \mathrm{C} / \mathrm{min}$, held for $1.5 \mathrm{~min}$; source and transfer line temperature $250^{\circ} \mathrm{C}$, and carrier gas helium at a $0.4 \mathrm{~mL} / \mathrm{min}$ constant flow rate. The impact energy was $70 \mathrm{eV}$. Data were acquired in full-scan mode in the range from 33 to $250 \mathrm{~m} / \mathrm{z}$ (dwell time $0.1 \mathrm{~s} / \mathrm{scan}$ ), and processed by Xcalibur v2.0 software (Thermo Fisher Scientific). Tentative identification of the compounds was done by comparison with standard reference mass spectra of the National Institute of Standards and Technology library (Gaithersburg, MD), and when available, it was confirmed by comparison to pure standards. Finally, the odor activity value (OAV) of the identified compounds was calculated by the ratio between concentration in the headspace/odor threshold in water. All analytical determinations were carried out in duplicate. Mean, standard deviation, and standard error of the mean were calculated and compared by the Tukey's test using Excel 2017 software (Microsoft Corp., Redmond, WA). The ANOVA and principal component analysis (PCA) were carried out by XL Stat software (Addinsoft SARL, New York, NY).

Besides the acidification technique, the cheeses also differed in the amount of rennet used, size of the curd grains, and whey drainage (Figure 1). Such variations are related to the different chemical and microbiologi- 
cal conditions under which cheesemaking is performed. In particular, (1) the amount or rennet is adapted to the $\mathrm{pH}$ value of milk for getting the required coagulation time $(15-20 \mathrm{~min})$. In direct acidification a reduced dose is needed, since the lower $\mathrm{pH}$ of milk tends to ac- celerate coagulation. (2) In traditional technology a greater size of curd grains is required to counterbalance the moisture losses caused by syneresis during fermentation; and (3) the whey is only partial removed in the traditional process for keeping the curd warm and fa-

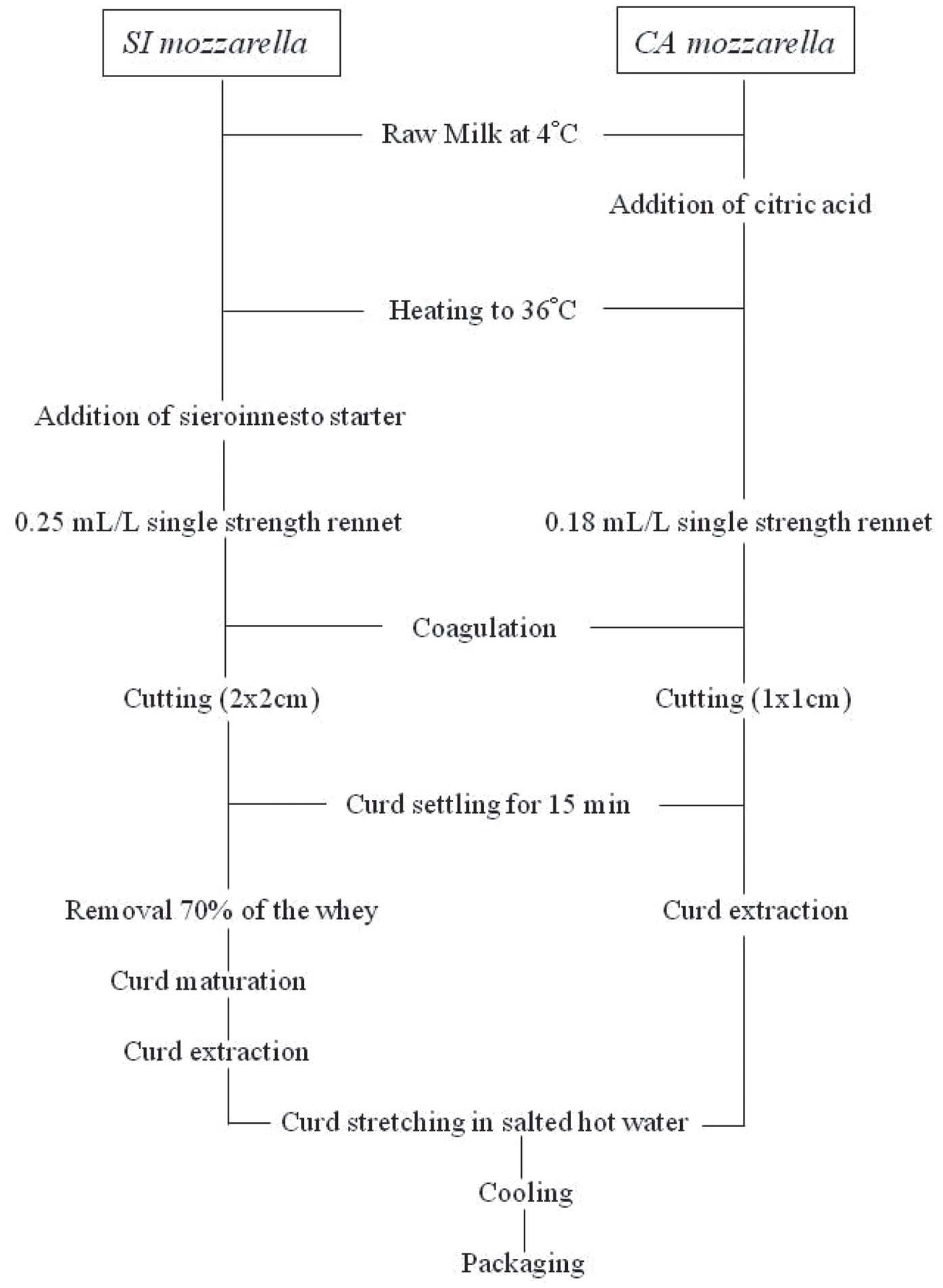

Figure 1. Technological scheme for mozzarella manufacturing. SI $=$ sieroinnesto; $\mathrm{CA}=$ citric acid. 
Table 1. Gross composition (mean $\pm \mathrm{SD}$ ) of mozzarella samples ${ }^{1}$

\begin{tabular}{lrrrr}
\hline Trial & $\mathrm{pH}$ & Moisture $(\%)$ & Protein $(\%)$ & Fat $(\%)$ \\
\hline CA1 & $6.00 \pm 0.03^{\mathrm{A}}$ & $58.61 \pm 1.26^{\mathrm{A}}$ & $18.28 \pm 0.89$ & $20.92 \pm 0.37^{\mathrm{A}}$ \\
SI1 & $5.56 \pm 0.05^{\mathrm{B}}$ & $56.45 \pm 0.85^{\mathrm{B}}$ & $18.54 \pm 0.92$ & $21.03 \pm 0.44^{\mathrm{A}}$ \\
CA2 & $5.91 \pm 0.02^{\mathrm{A}}$ & $61.26 \pm 4.03^{\mathrm{A}}$ & $17.56 \pm 2.21$ & $14.70 \pm 2.07^{\mathrm{B}}$ \\
SI2 & $5.37 \pm 0.04^{\mathrm{C}}$ & $53.74 \pm 2.07^{\mathrm{C}}$ & $21.68 \pm 2.40$ & $18.53 \pm 2.27^{\mathrm{A}}$ \\
CA3 & $6.01 \pm 0.01^{\mathrm{A}}$ & $59.34 \pm 2.20^{\mathrm{A}}$ & $17.69 \pm 2.28$ & $15.27 \pm 0.75^{\mathrm{B}}$ \\
SI3 & $5.61 \pm 0.02^{\mathrm{B}}$ & $55.20 \pm 1.12^{\mathrm{BC}}$ & $19.90 \pm 1.28$ & $16.65 \pm 0.65^{\mathrm{B}}$ \\
Mean CA (SEM) & $6.0(0.03)$ & $59.7(1.02)$ & $17.8(0.73)$ & $17.0(0.44)$ \\
Mean SI (SEM) & $5.5(0.05)$ & $55.1(0.69)$ & $20.0(0.63)$ & $18.7(0.46)$ \\
\hline
\end{tabular}

${ }^{\mathrm{A}-\mathrm{C}}$ Values in the same column with different superscripts are different at $P<0.05$.

${ }^{1}$ CA1,2,3 = mozzarella made by direct acidification (citric acid); SI1,2,3 = mozzarella made by sieroinnesto fermentation (natural whey starter).

voring microbial activity. The total processing times were very different: the average time for curd maturation (from end of curd settling to stretching) was 17 min for direct acidification and $205 \mathrm{~min}$ for SI. The chemical and microbiological characteristics of the milk used in the trials were rather constant: the mean values (SD) were $3.71 \%(0.13)$ fat, $3.18 \%(0.04)$ protein, 8.3 $(0.34) \times 10^{4} \mathrm{cfu} / \mathrm{mL}$ total viable counts, $2.5(0.54) \times$ $10^{5} \mathrm{SCC} / \mathrm{mL}$. Some variability was found in the characteristics of the starter: acidity varied from 38 to 52 Soxhlet-Henkel degrees $/ 100 \mathrm{~mL}$, and the counts of the different microbial groups roughly varied in the order of a maximum of $0.5 \mathrm{log}$ units. Variability in the composition of autochthonous starter for mozzarella is normal and is connected with periodic changes of the microbiological characteristics of the milk used and of the environmental conditions during preparation (Morea et al., 1999). On the whole, the starters used in the 3 trials had the following common traits: (1) lactobacilli were the dominant microorganisms $\left(\approx 1.5 \times 10^{7} \mathrm{cfu} / \mathrm{mL}\right)$, followed by lactococci $\left(\approx 5.0 \times 10^{6} \mathrm{cfu} / \mathrm{mL}\right)$, enterococci $\left(\approx 1.3 \times 10^{6} \mathrm{cfu} / \mathrm{mL}\right)$, and streptococci $(\approx 1.0 \times$ $\left.10^{6} \mathrm{cfu} / \mathrm{mL}\right) ;(2)$ the spoilage bacteria were poorly present; and (3) yeasts and molds always represented important secondary components $\left(\approx 0.9 \times 10^{6} \mathrm{cfu} / \mathrm{mL}\right)$. The gross composition of the cheeses is shown in Table 1. The main differences between the 2 groups regarded $\mathrm{pH}$ : it depends on the fact that the 2 acidification methods follow different kinetic of casein demineralization. Direct acidification is more effective at sequestering calcium from the casein micelle, and allows stretching to be performed at higher $\mathrm{pH}$ (Mucchetti and Neviani, 2006). This depends on the fact that when the acid is added to milk it immediately acts on the micelles suspended in the water medium, sequestering part of the intra-micellar colloidal calcium phosphate. In contrast, in traditional technology lactic acid is slowly released in the curd by starter fermentation and reaches the casein micelles after coagulation. In this case the micelles are concentrated into the paracaseinate network, connected among them by inter-micellar calcium bridges: the colloidal calcium/casein ratio is higher, and more acid is needed to perform the sequestering reaction. Table 2 shows the microbial counts in the cheese samples. The microbiota of the CA cheese was mainly composed of adventitious spoilage microorganisms, whereas lactic acid bacteria dominated the profiles of SI mozzarella. Such differences gave rise to well-differentiated sensory characteristics, as shown in Table 3. During the training sessions, 14 attributes were selected by the panelists: 3 regarded texture (appearance, elasticity, hardness), 5 odor (odor intensity, fresh and sour milk, buttery, fruit/vegetable), and 6 taste (taste intensity, sweet, savory, bitter, sour, and aftertaste). The panel decided to merge the fruit and vegetable descriptors into a single attribute to make a

Table 2. Mean values $(\log \mathrm{cfu} / \mathrm{g})$ for microbial counts in the cheese samples ${ }^{1}$

\begin{tabular}{|c|c|c|c|c|c|c|c|}
\hline Item & MLAB & TLAB & LAC & STR & $\mathrm{EC}$ & ENT & $\mathrm{Y} \& \mathrm{M}$ \\
\hline$\overline{\mathrm{CA} 1}$ & $3.2 \pm 0.1^{\mathrm{A}}$ & $3.1 \pm 0.1^{\mathrm{A}}$ & $\mathrm{ND}^{2}$ & $1.9 \pm 0.1^{\mathrm{A}}$ & ND & $3.2 \pm 0.1^{\mathrm{C}}$ & $1.0 \pm 0.3^{\mathrm{A}}$ \\
\hline SI1 & $5.6 \pm 0.2^{\mathrm{B}}$ & $6.4 \pm 0.3^{\mathrm{B}}$ & $2.3 \pm 0.2$ & $6.0 \pm 0.3^{\mathrm{C}}$ & $2.9 \pm 0.2$ & $1.8 \pm 0.1^{\mathrm{B}}$ & $2.7 \pm 0.2^{\mathrm{B}}$ \\
\hline $\mathrm{CA} 2$ & $3.1 \pm 0.1^{\mathrm{A}}$ & $2.9 \pm 0.3^{\mathrm{A}}$ & ND & $3.0 \pm 0.1^{\mathrm{B}}$ & ND & $2.8 \pm 0.3^{\mathrm{C}}$ & $1.5 \pm 0.2^{\mathrm{A}}$ \\
\hline CA3 & $3.0 \pm 0.1^{\mathrm{A}}$ & $3.2 \pm 0.1^{\mathrm{A}}$ & ND & $2.0 \pm 0.1^{\mathrm{A}}$ & ND & $3.7 \pm 0.1^{\mathrm{D}}$ & $1.5 \pm 0.2^{\mathrm{A}}$ \\
\hline SI3 & $5.6 \pm 0.1^{\mathrm{B}}$ & $6.2 \pm 0.2^{\mathrm{B}}$ & $1.9 \pm 0.3$ & $6.2 \pm 0.2^{\mathrm{C}}$ & $2.9 \pm 0.1$ & $1.3 \pm 0.1^{\mathrm{A}}$ & $2.9 \pm 0.1^{\mathrm{B}}$ \\
\hline
\end{tabular}

${ }^{\mathrm{A}-\mathrm{D}}$ Values in the same column with different superscripts are different at $P<0.05$.

${ }^{1} \mathrm{CA} 1,2,3=$ mozzarella made by direct acidification (citric acid); SI1,2,3 = mozzarella made by sieroinnesto fermentation (natural whey starter); $\mathrm{MLAB}=$ mesophilic lactobacilli; TLAB = thermophilic lactobacilli; LAC = lactococci; STR = streptococci; EC = enterococci; ENT = enterobacteria; Y\&M = yeasts and molds.

${ }^{2}$ Not detected. 
Table 3. Sensory profile of traditional (SI) and industrial (CA) highmoisture mozzarella (mean values of 3 cheesemaking trials) ${ }^{1}$

\begin{tabular}{lccc}
\hline Attribute & SI & CA & Sig \\
\hline Appearance & 4 & 3 & \\
Hardness & 1 & 1 & $*$ \\
Elasticity & 3 & 2 & $*$ \\
Odor intensity & 3 & 1 & \\
Fresh milk & 1 & 2 & $*$ \\
Sour milk & 1 & 0 & $*$ \\
Butter & 2 & 1 & $*$ \\
Fruit/vegetable & 2 & 0 & $*$ \\
Taste intensity & 3 & 1 & $*$ \\
Sweet & 1 & 2 & \\
Savory & 2 & 1 & \\
Bitter & 1 & 0 & $*$ \\
Sour & 2 & 0 & $*$ \\
Aftertaste & 3 & 1 &
\end{tabular}

${ }^{1} 0=$ not perceived; $4=$ highly perceived; Sig $=$ statistical significance of the difference $\left({ }^{*} P<0.05\right)$.

synthesis of different opinions. The results obtained demonstrated that the cheeses were clearly discriminated in all of the 3 cheesemaking trials. Traditional mozzarella received higher scores for almost all attributes and was described as elastic, with butter, sour milk and fruity/vegetable odor, and slight sour taste. In contrast, direct set mozzarella was less elastic, with delicate/fresh milk odor, and sweetish notes. This finding suggests that sensory analysis allows one to easily differentiate between traditional mozzarella and the industrial mozzarella, and should be recommended for official checking of commercial products. As far as VOC
Table 4. Abundance of the volatile organic compound chemical classes in high-moisture mozzarella, expressed as $\mu \mathrm{g} / \mathrm{kg}$ headspace volume (mean values $\pm \mathrm{SD})^{1}$

\begin{tabular}{lcc}
\hline Chemical class & CA & SI \\
\hline Ketones & $284.7 \pm 8.3^{\mathrm{B}}$ & $1,041.6 \pm 70.2^{\mathrm{A}}$ \\
Aldehydes & $179.4 \pm 16.1^{\mathrm{B}}$ & $370.6 \pm 9.3^{\mathrm{A}}$ \\
Alcohols & $148.8 \pm 3.1^{\mathrm{B}}$ & $595.6 \pm 72.9^{\mathrm{A}}$ \\
Acids & $129.3 \pm 11.3^{\mathrm{B}}$ & $312.7 \pm 33.3^{\mathrm{A}}$ \\
Terpenes & $51.1 \pm 4.4^{\mathrm{B}}$ & $35.3 \pm 5.75$ \\
Esters & $8.8 \pm 2.2^{\mathrm{B}}$ & $348.0 \pm 71.9^{\mathrm{A}}$ \\
Sulfur compounds & $9.0 \pm 0.6^{\mathrm{A}}$ & $2.9 \pm 0.4^{\mathrm{B}}$ \\
Miscellaneous & $118.1 \pm 15.5^{\mathrm{B}}$ & $151.9 \pm 19.6^{\mathrm{A}}$ \\
Total & $929.2^{\mathrm{B}}$ & $2,858.6^{\mathrm{A}}$ \\
\hline
\end{tabular}

$\overline{\mathrm{A}, \mathrm{B}}$ Values in the same row with different superscripts are different at $P<0.05$.

${ }^{1} \mathrm{CA}=$ mozzarella made by direct acidification (citric acid); $\mathrm{SI}=$ mozzarella made by sieroinnesto fermentation (natural whey starter).

are concerned, 51 volatile compounds were identified in the entire set of samples, grouped in 8 chemical classes (Table 4). A 3 times higher concentration of volatiles was observed in the traditional product, with carbonyl compounds representing a relevant part of the volatile fraction in both types of cheese. Several pathways can be hypothesized for aldehyde and ketone formation in HMM: apart some transfer from milk, the primary source should be lactose and CA fermentation (Rodriguez et al., 2009; Cheng, 2010), whereas the lipolytic way should be negligible because mozzarella is a fresh cheese. This hypothesis was supported by the concentrations found in $\mathrm{CA}$, which roughly corresponded to

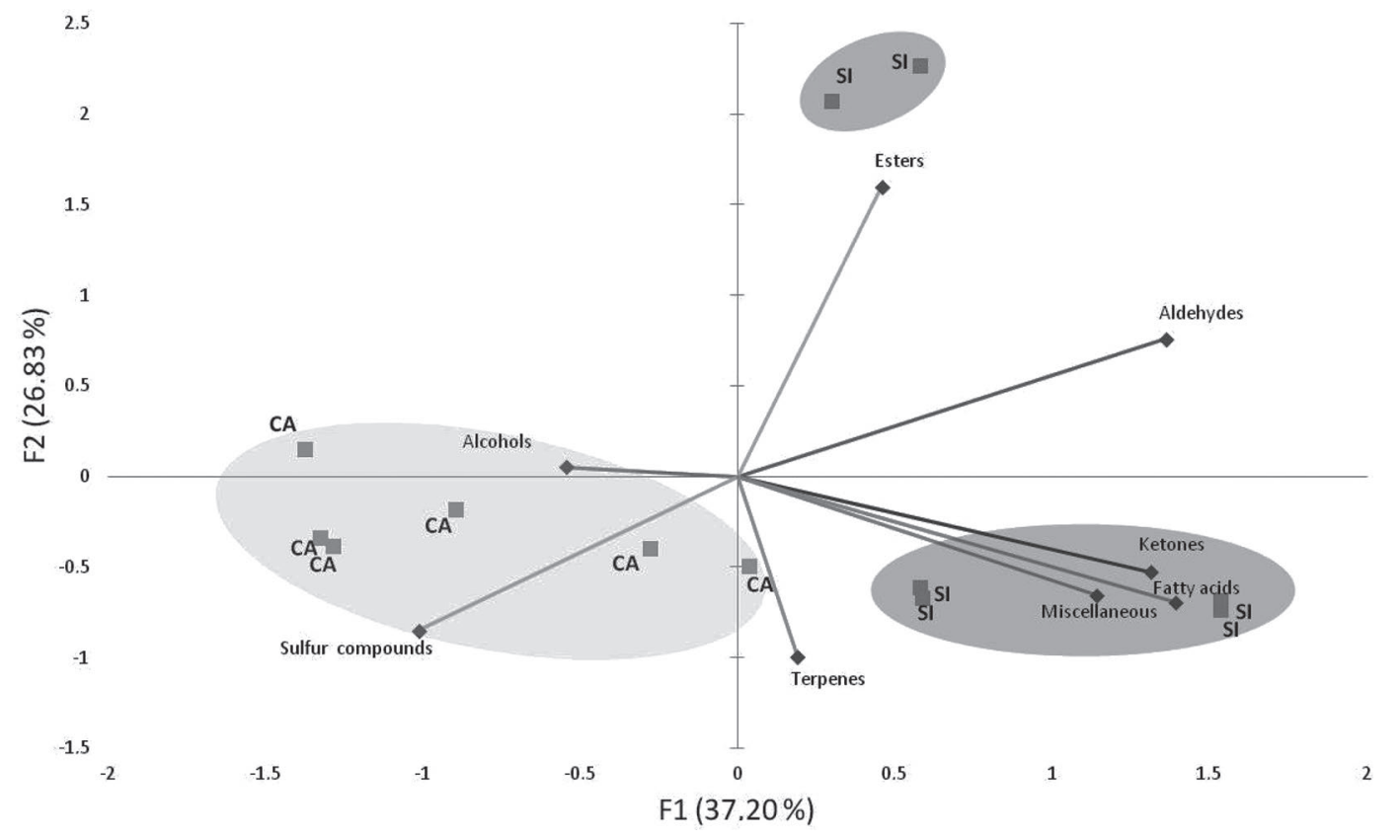

Figure 2. Principal component analysis of volatile organic compounds of mozzarella samples. SI $=$ sieroinnesto; CA $=$ citric acid; F1 $=$ principal component $1 ; \mathrm{F} 2=$ principal component 2 . 
Natrella et al.: SHORT COMMUNICATION: PROFILE OF HIGH-MOISTURE MOZZARELLA

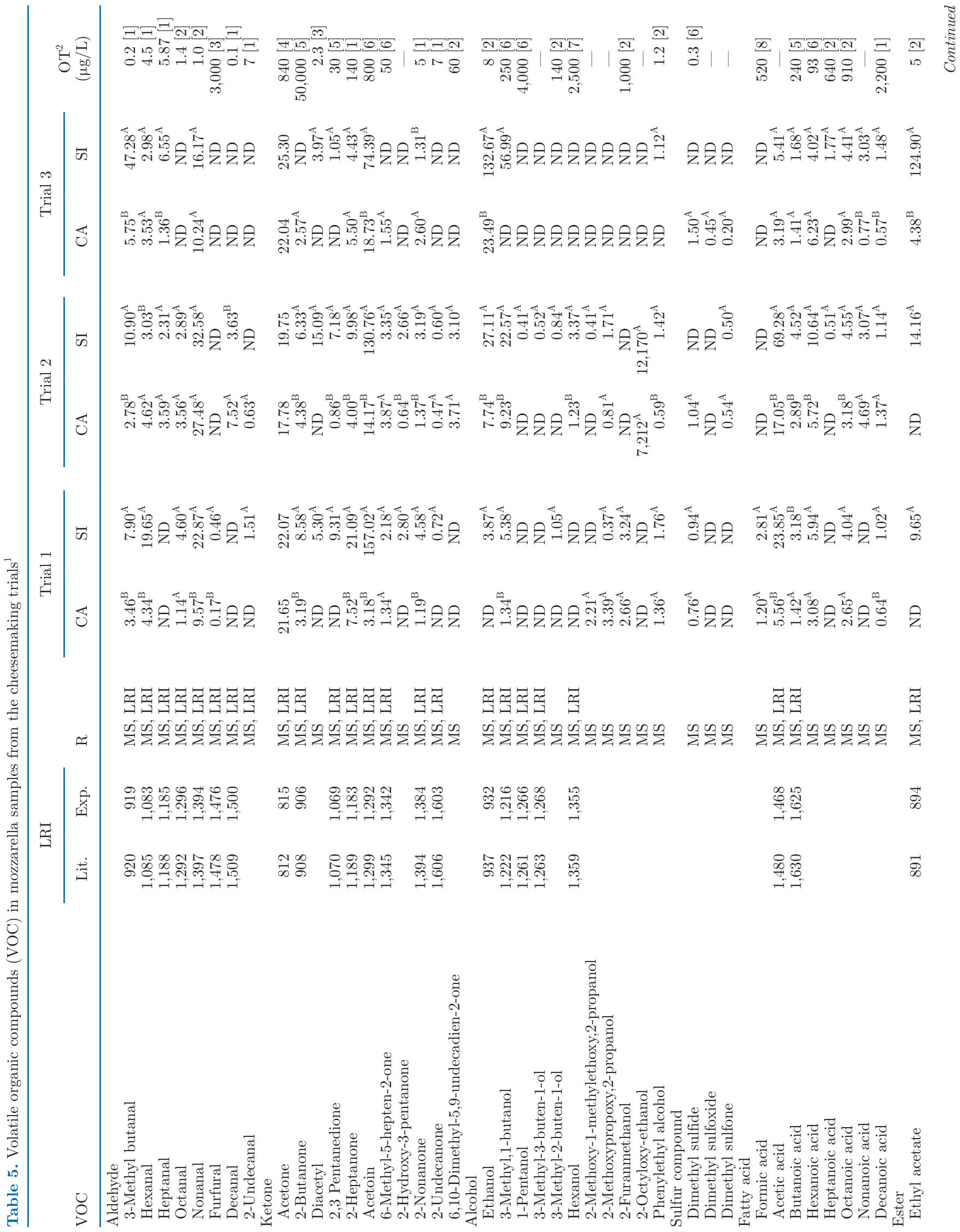




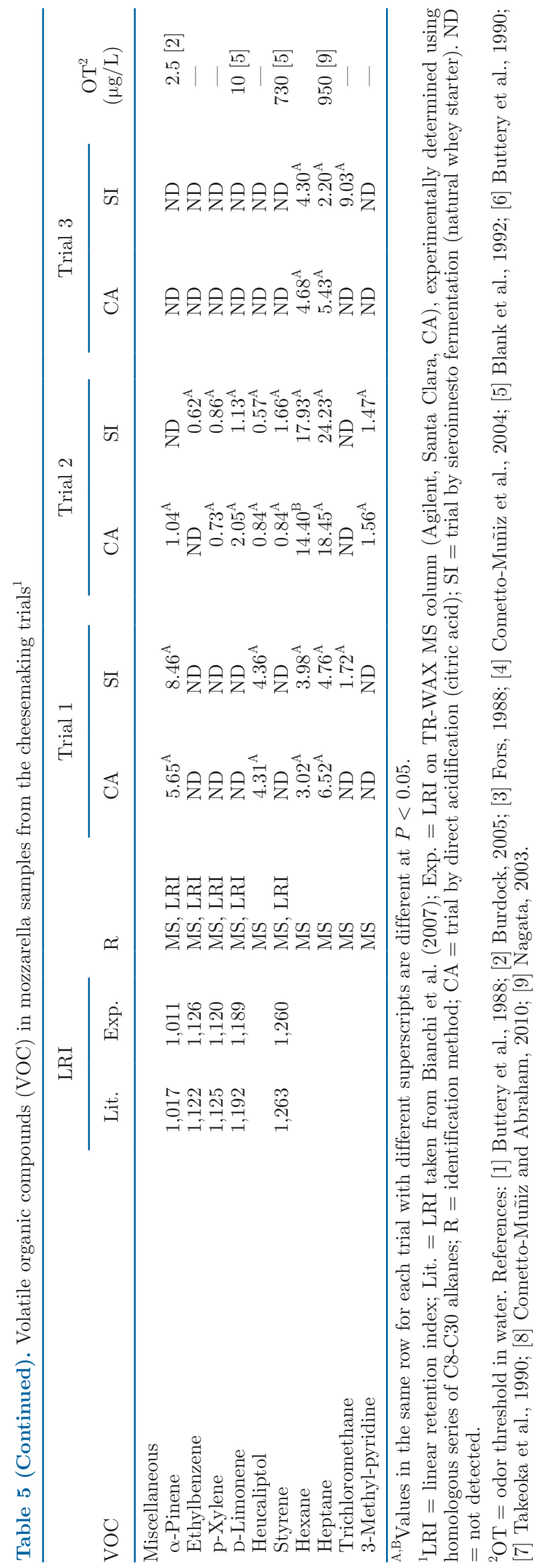

those reported by Toso et al. (2002) in refrigerated raw milk. Alcohols and acids represented another important part of the VOC mixture, followed by esters that derive from their condensation. Esters are powerful odorants in milk and cheeses, having a low odor threshold (Moio et al., 1993b; Curioni and Bosset, 2002). Their concentration in the SI samples corresponded to about $38 \%$ of the sum of the above precursors, against only $3 \%$ in CA samples, suggesting that their formation should be microbiologically mediated. Elaboration of the data by PCA allowed clear separation of the samples (Figure 2 ). The PCA explained $64 \%$ of variance, $37 \%$ of which was along the first component and $27 \%$ along the second component. Along principal component 1, all SI samples were positioned in the positive quadrant due to higher richness of compounds, whereas the CA samples were in the negative quadrant. Principal component 2 allowed clustering of the SI samples into 2 subgroups, one of which laid in the positive area due to higher level of esters, indicating some heterogeneity for the traditional cheese samples. As to the single VOC (Table 5 ), the only qualitative differences between technologies regarded diacetyl and 3-methyl-2-buten-1-ol, which were only detected in traditional mozzarella. Besides these 2 compounds, the SI samples were discriminated from CA by higher concentrations of acetoin and related conversion product 2-butanone, 3-methyl butanal, 2-3 pentanedione, and 2-nonanone. Other discriminative compounds were ethanol, 3-methyl-1-butanol, acetic, butanoic, and decanoic acids. Also ethyl acetate was a good discriminant compound, which is predictable considering the high concentration of its precursors in traditional mozzarella. To estimate the role of VOC on flavor, previously published threshold data were applied with relative abundance results to generate estimated OAV. Table 6 shows the possible aromatic backbone of the cheeses, composed of the aromaactive compounds with OAV $>1$. Some of them exceeded the value in all cheesemaking trials, others only in 2 or just 1. In particular, 3-methyl butanal, nonanal, diacetyl, and ethyl acetate always acted as aroma-active compounds, whereas hexanal, heptanal, octanal, ethanol, and phenylethyl alcohol exceeded value 1 in 2 trials. The results agree with those reported by other authors in studies on fresh or model cheeses (Urbach, 1997; Ruggirello et al., 2018), but a specific outcome of the present study regarded 3-methyl-butanal. It was found to be the most relevant key compound in mozzarella: it has malty/nutty/fresh cheese odor and is much more present in the traditional product, in which can be formed both by lactic acid bacteria and yeast metabolism (Afzal et al., 2017). The other key compounds, hexanal, eptanal, and nonanal, are responsible for green/grass odor; ethyl acetate has ethereal and 
Table 6. Volatile organic compounds (VOC) exceeding value 1 for odor activity value in traditional (SI) and direct acidification (CA) mozzarella, odor threshold in water $(\mathrm{OT})$, and relative odor description ${ }^{1}$

\begin{tabular}{|c|c|c|c|c|c|c|c|c|c|c|c|}
\hline \multirow[b]{2}{*}{ VOC } & \multicolumn{3}{|c|}{ Trial 1} & \multicolumn{3}{|c|}{ Trial 2} & \multicolumn{3}{|c|}{ Trial 3} & \multirow{2}{*}{$\begin{array}{c}\mathrm{OT} \\
(\mu \mathrm{g} / \mathrm{L})\end{array}$} & \multirow[b]{2}{*}{ Odor description } \\
\hline & SI & $\mathrm{CA}$ & Sig & SI & $\mathrm{CA}$ & Sig & SI & $\mathrm{CA}$ & Sig & & \\
\hline Hexanal & 4.4 & 1.0 & $*$ & - & 1.0 & * & - & - & & 4.5 & Green, fatty, fruity \\
\hline Heptanal & - & - & & - & 1.2 & & 2.2 & - & * & 5.87 & Fatty, fruity \\
\hline Octanal & 3.3 & - & $*$ & 2.1 & 2.5 & & - & - & & 1.4 & Fruity \\
\hline Nonanal & 22.9 & 9.6 & $*$ & 32.6 & 27.5 & & 16.2 & 10.2 & & 1.0 & Fatty, citrus, green \\
\hline Ethanol & - & - & & 3.4 & 1.0 & * & 16.6 & 2.9 & $*$ & 8.0 & Pleasant, fragrant, alcohol \\
\hline Phenylethyl alcohol & 1.5 & 1.1 & & 1.2 & - & $*$ & - & - & & 1.2 & Rose \\
\hline Dimethyl sulfide & - & - & & - & 3.5 & $*$ & - & 5.0 & $*$ & 0.3 & $\begin{array}{l}\text { Unpleasant wild radish, } \\
\text { cabbage }\end{array}$ \\
\hline Ethyl acetate & 1.9 & - & & 2.8 & - & $*$ & 25.0 & - & $*$ & 5.0 & Pineapple \\
\hline$\alpha$-Pinene & 3.4 & 2.3 & & - & - & & - & - & & 2.5 & Pine, turpentine \\
\hline
\end{tabular}

${ }^{1}$ Sig $=$ significantly different at $* P<0.05$. For OT details, see Table 5 .

fruity notes; diacetyl is well known as being responsible for butter odor; and phenylethanol has a rose/flowery odor. This latter derives from phenylalanine metabolism (Smit et al., 2005) and has been reported to be an important aromatic compound of buffalo mozzarella, in which it is produced by some lactococcal and Streptococcus thermophilus strains and yeasts (Moio et al., 1993b; Mauriello et al., 2003).

In conclusion, the present study suggested that traditional mozzarella can be discriminated both by sensory and SPME-GC/MS analysis. The results obtained can be very useful in view of European Union PDO labeling of the traditional product, when the question of protecting it from imitations will arise. Further research is needed to validate the results on commercial samples.

\section{ACKNOWLEDGMENTS}

Michele Faccia, Giuseppe Natrella, Josè Lorenzo, Pasquale De Palo, and Giuseppe Gambacorta contributed equally to this work. The research was funded by the University of Bari, Italy. The authors declare having no conflicts of interest.

\section{REFERENCES}

Afzal, M. I., C. C. Gonzalez Ariceaga, K. Boulahya, M. Jacquot, S. Delaunay, and C. Cailliez-Grimal. 2017. Biosynthesis and role of 3-methylbutanal in cheese by lactic acid bacteria: Major metabolic pathways, enzymes involved, and strategies for control. Crit. Rev. Food Sci. Nutr. 57:399-406. https://doi.org/10.1080/10408398 .2014 .893502 .

Bianchi, F., M. Careri, A. Mangia, and M. Musci. 2007. Retention indices in the analysis of food aroma volatile compounds in temperature-programmed gas chromatography: Database creation and evaluation of precision and robustness. J. Sep. Sci. 30:563-572. https://doi.org/10.1002/jssc.200600393.

Blank, I., A. Sen, and W. Grosch. 1992. Aroma impact compounds of arabica and robusta coffee. Qualitative and quantitative inves- tigations. Pages 117-129 in 14th Int. Colloq. Chem. Coffee, San Francisco, CA. Association for Science and Information on Coffee, Allenwinden, Switzerland.

Burdock, G. A. 2005. Fenaroli's handbook of flavor ingredients. Food and Cosmetics Toxicology (Vol. 14). CRC Press, Boca Raton, FL.

Buttery, B. G., J. G. Turnbaugh, and L. C. Ling. 1988. Contribution of volatiles to rice aroma. J. Agric. Food Chem. 36:1006-1009. https: //doi.org/10.1021/jf00083a025.

Buttery, R. G., R. Teranishi, L. C. Ling, and J. G. Turnbaugh. 1990. Quantitative and sensory studies on tomato paste volatiles. J. Agric. Food Chem. 38:336-340. https://doi.org/10.1021/jf00091a074.

Cheng, H. 2010. Volatile flavor compounds in yogurt: A review. Crit. Rev. Food Sci. Nutr. 50:938-950. https://doi.org/10.1080/ 10408390903044081.

Cometto-Muñiz, J. E., and M. H. Abraham. 2010. Structure activity relationships on the odor detectability of homologous carboxylic acids by humans. Exp. Brain Res. 207:75-84. https://doi.org/10 $.1007 / \mathrm{s} 00221-010-2430-0$.

Cometto-Muñiz, J. E., W. S. Cain, and M. H. Abraham. 2004. Detection of single and mixed VOC's by smell and by sensory irritation. Indoor Air 14(s8):108-117. https://doi.org/10.1111/j.1600-0668 2004.00297.x.

Curioni, P. M. G., and J. O. Bosset. 2002. Key odorants in various cheese types as determined by gas chromatography-olfactometry. Int. Dairy J. 12:959-984. https://doi.org/10.1016/S0958 $-6946(02) 00124-3$

EU (European Commission). 2017. Application for PDO n. IT/ PDO/0005/2384. http://ec.europa.eu/agriculture/quality/door/ appliedName.html?denominationId $=21429 \&$ locale $=$ en.

Faccia, M., A. Trani, and A. Di Luccia. 2009. Relationships between milk quality and acidification in the production of table Mozzarella without starters. J. Dairy Sci. 92:4211-4217. https://doi.org/ 10.3168/jds.2009-2154.

Fors, S. 1988. Sensory properties of volatile Maillard reaction products and related compounds. Pages 185-286 in The Maillard Reaction in Foods and Nutrition. ACS Symposium Series 215. G. R. Waller and M. S. Feather, ed. ACS, Washington, DC.

Gasperi, F., G. Gallerani, A. Boschetti, F. Biasioli, A. Monetti, E. Boscaini, A. Jordan, W. Lindinger, and S. Iannotta. 2001. The mozzarella cheese flavour profile: A comparison between judge panel analysis and proton transfer reaction mass spectrometry. J. Sci. Food Agric. 81:357-363. https://doi.org/10.1002/1097 -0010(200102)81:3<357::AID-JSFA818>3.0.CO;2-O.

IDF (International Dairy Federation). 1991. Milk and Milk Products. Enumeration of Microorganisms. Colony Count at $30^{\circ} \mathrm{C}$. IDF Standard 100b, FIL-IDF, Brussels, Belgium.

ISO (International Standard Organization). 1993. Sensory analysis: General guidance for the selection, training and monitoring of as- 
sessors. Part 1: Selected assessors. ISO 8586-1, Geneva, Switzerland.

Mauriello, G., L. Moio, A. Genovese, and D. Ercolini. 2003. Relationships between flavoring capabilities, bacterial composition, and geographical origin of natural whey cultures used for traditional water-buffalo Mozzarella cheese manufacture. J. Dairy Sci. 86:486497. https://doi.org/10.3168/jds.S0022-0302(03)73627-3.

Moio, L., J. Dekimpe, P. X. Etievant, and F. Addeo. 1993a. Comparison of the neutral volatile compounds in mozzarella cheese made from bovine and water buffalo milk. Ital. J. Food Sci. 3:215-225.

Moio, L., D. Langlois, P. Etievant, and F. Addeo. 1993b. Powerful odorants in bovine, ovine, caprine and water buffalo milk determined by means of gas chromatography-olfactometry. J. Dairy Res. 60:215-222. https://doi.org/10.1017/S0022029900027527.

Morea, M., F. Baruzzi, and P. S. Cocconcelli. 1999. Molecular and physiological characterization of dominant bacterial populations in traditional Mozzarella cheese processing. J. Appl. Microbiol. 87:574-582. https://doi.org/10.1046/j.1365-2672.1999.00855.x.

Mucchetti, G., and E. Neviani. 2006. I formaggi a pasta filata. Pages 336-356 in Microbiologia e Tecnologia Lattiero-Casearia. G. Mucchetti and E. Neviani, ed. Tecniche Nuove, Milan, Italy.

Nagata, Y. 2003. Measurement of odor threshold by triangle odor bag method. Pages 118-127 in Odor measurement review. Japan: Office of Odor, Noise and Vibration, Environmental Management Bureau, Ministry of the Environment, Government of Japan.

Pisano, M. B., P. Scano, A. Murgia, S. Cosentino, and P. Caboni. 2016. Metabolomics and microbiological profile of Italian mozzarella cheese produced with buffalo and cow milk. Food Chem. 192:618-624. https://doi.org/10.1016/j.foodchem.2015.07.061.

Rodriguez, A., B. Martinez, and J. E. Suarez. 2009. Dairy starter cultures. Pages 31-48 in Handbook of Animal-Based Fermented
Food and Beverage Technology. 2nd ed. Y. H. Hui, ed. CRC Press, Boca Raton, FL.

Ruggirello, M., M. Giordano, M. Bertolino, I. Ferrocino, L. Cocolin, and P. Dolci. 2018. Study of Lactococcus lactis during advanced ripening stages of model cheeses characterized by GC-MS. Food Microbiol. 74:132-142. https://doi.org/10.1016/j.fm.2018.03.012.

Smit, G., B. A. Smit, and W. J. M. Engels. 2005. Flavour formation by lactic acid bacteria and biochemical flavour profiling of cheese products. FEMS Microbiol. Rev. 29:591-610. https://doi.org/10 .1016/j.fmrre.2005.04.002.

Takeoka, G. R., R. A. Flath, T. R. Mon, R. Teranishi, and M. Guentert. 1990. Volatile constituents of apricot (Prunus armeniaca). J. Agric. Food Chem. 38:471-477. https://doi.org/10.1021/ jf00092a031.

Toso, B., G. Procida, and B. Stefanon. 2002. Determination of volatile compounds in cows' milk using headspace GC-MS. J. Dairy Res. 69:569-577. https://doi.org/10.1017/S0022029902005782.

Trani, A., G. Gambacorta, P. Loizzo, A. Cassone, and M. Faccia. 2016. Un contributo alla caratterizzazione della treccia pugliese a sieroinnesto. Ind. Aliment. 569:3-10.

Urbach, G. 1997. The flavour of milk and dairy products: 11. Cheese: Contribution of volatile compounds. Int. J. Dairy Technol. 50:7989. https://doi.org/10.1111/j.1471-0307.1997.tb01743.x.

\section{ORCIDS}

M. Faccia @ https://orcid.org/0000-0001-9496-9151

P. De Palo @ https://orcid.org/0000-0002-5612-1691 